\title{
SUSTAINABILITY LESSONS FROM VERNACULAR ARCHITECTURE IN FREI OTTO'S WORK: TENTS AND GRIDSHELLS
}

\author{
J. M. Songel ${ }^{1, *}$ \\ ${ }^{1}$ Research Centre PEGASO, Universitat Politècnica de València, Valencia, Spain - jsongel@cpa.upv.es
}

Commission II - WG II/8

KEY WORDS: Frei Otto, Tents, Yurts, Gridshells, Light Structures, Sustainability, Vernacular Architecture

\begin{abstract}
:
Frei Otto is usually linked in the historiography of modern architecture to the German Pavilion for the Montreal Expo and the Olympic Stadium in Munich, a couple of works that have typically been regarded as predecessors of High-Tech architecture. But his contribution to architecture goes far beyond these worldwide famous works and can better be traced in his rich experience at the Institute for Lightweight Structures in Stuttgart, as an insightful observer of natural and man-made objects and as an investigator of the relationship between form, force and mass. He has developed new types of structures which often refer to primitive building types and can therefore be easily found in vernacular architecture: tents, nets, gridshells, branching constructions, folding roofs, umbrellas, as well as pneumatic and suspended constructions. All of them are the outcome of a very thorough process of investigation at his institute, which usually also included a survey of these building types in vernacular architecture. The target of this paper is to explore this relationship, and to test whether the strive for lightness can be regarded as a common ground between vernacular architecture and Frei Otto's work. In any case, his endeavour to get the maximum with the minimum, to achieve a lot from a little, is also a key target of sustainability and an essential feature of vernacular architecture.
\end{abstract}

\section{INTRODUCTION}

When considering sustainability in vernacular architecture, one key feature refers to austerity and a wise use of materials, trying to take full advantage of their physical behaviour and reach optimal performance. There is an urge to make the most out of a limited amount of materials available. This endeavour to get the most out of the least connects vernacular architecture with a tradition towards lightness developed by pioneering civil and structural engineers, in an effort to increase efficiency and strength with ever weight-reducing structural elements. One of these pioneering engineers, Robert Le Ricolais, expressed the target of this trend towards this utopian ideal in simple words: "zero weight, infinite span". His approach to structure is also very indicative of his strive for lightness: "the art of structure is how and where to put the holes. It's a good concept for building, to build with holes, to use things which are hollow, things which have no weight, which have strength but no weight" (Le Ricolais, 1997).

If we search in the world of vernacular architecture, we can also find outstanding examples of efficient light structures, which are often within the field of nomadic architecture. Indeed, shepherds, hunters or other nomad people need to move their home constantly, and if they carry it with them, it will inevitably have to be a light structure. Some of the best known examples of this movable and deployable architecture, like tents or yurts, have in fact been considered by architectural historians and theoreticians as archetypes of architecture.

These primitive building types also inspired a contemporary champion of lightness and structural efficiency: the German architect, engineer, inventor and researcher Frei Otto (19252015). He founded in 1964 the Institute for Lightweight Structures at the University of Stuttgart, where he carried out much of his research on light structures.
His definition of lightweight construction - Leichtbau - as "a way of building with a minimum consumption of material, energetic, and economic means" (Otto, 2010) could easily be identified as one of the key principles of vernacular or sustainable architecture.

In this paper, we intend to explore the extent to which this primitive architecture influenced the work of Frei Otto, and the developments that he brought to this age-old tradition and to modern architecture, through the strive for lightness and efficiency of civil and structural engineers.

\section{TENTS AND MEMBRANE STRUCTURES}

\subsection{Types of tents}

According to the specialized bibliography (Burkhardt, 2000) and (Drew, 1979), from the point of view of structure and form, there are two main types of tents: framed and prestressed. The main difference between them lies on the role played by the structural support and the enclosure.

In framed tents there is a specific arrangement of rigid rods subject to bending, compression or tension, which makes up a stable frame on which the enclosure is laid. The tent assembly process involves two subsequent and independent actions: first the frame is erected and secured, and then a limp non-prestressed enclosure made up of a skin or fabric membrane is laid and fastened. The areas of textile covering are tensioned or hung and form a flat or singly-curved surface. Form and structure of traditional tents correspond to this type of framed tents (Figure 1).

\footnotetext{
* Corresponding author
} 
In prestressed tents structure and enclosure are integrated and behave as a single structural element, shaping and enclosing space. The textile membrane is prestressed in tension and supported on masts, arches or beams, all the elements being assembled simultaneously. Form and structure become a unified entity. Strength and stiffness of these membranes develops from a very characteristic form: anticlastic doubly-curved surfaces, also known as saddles. This type of tents corresponds to modern designs and principles developed by Frei Otto from 1954 onwards.

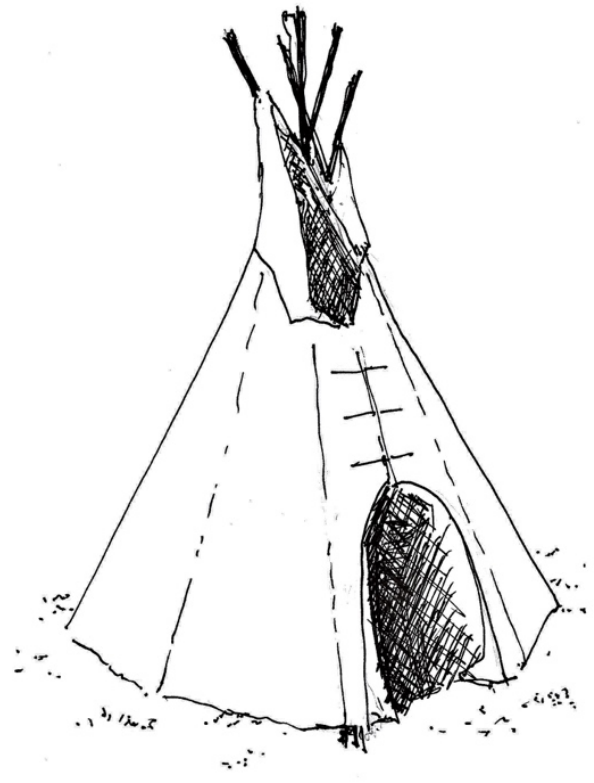

Tipi tent

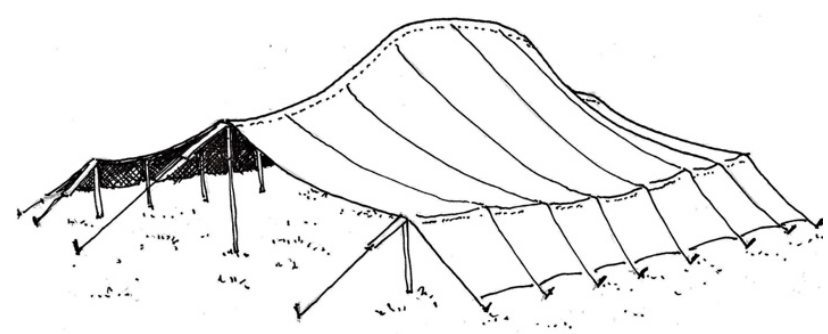

Bedouin tent

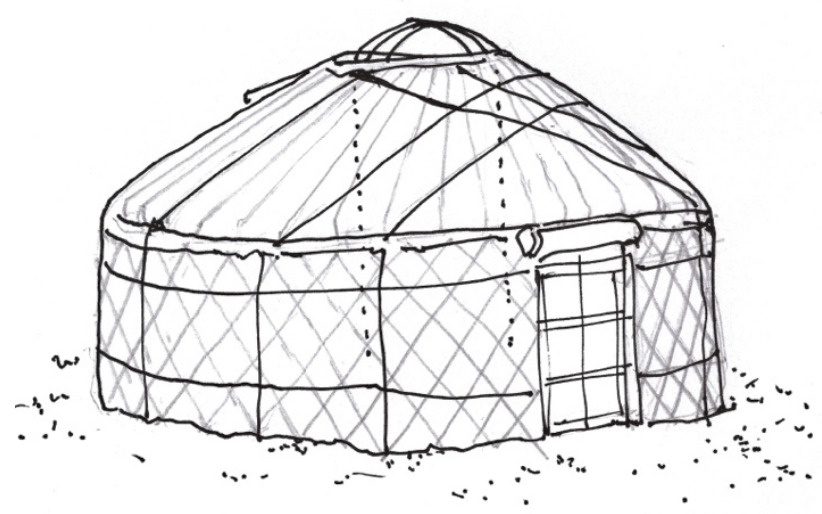

Kyrgyz yurt

\subsection{Types of prestressed tents}

After graduating as an architect in Berlin, Frei Otto wrote his doctoral dissertation on tensioned structures, which was later published in 1954 as a book titled Das hängende Dach (Hanging roofs). A fruitful contact with the most important German tent manufacturing company - L. Stromeyer \& Co. brought about the development of unprecedented forms and technologies for tents, a building type which had so far stayed within the field of ephemeral, traditional and nomad architecture enclosing small spaces with short spans. New prestressed membrane structures appeared, covering larger spans and providing more endurance to this building type.

Membrane roofs are extremely lightweight, and therefore the main problem is no longer dead load, as much as form stability. Framed or hanging membranes can flap easily when wind blows, so the challenge is how to fix permanently the position of every point of the membrane. Once again in the history of structures, geometric form can become a key ally of strength. Doubly curved anticlastic surfaces, or saddle geometries, were the forms Frei Otto explored to stiffen membranes. If they are prestressed to produce such shapes, each point in the membrane is crossed by two opposing forces trying to move it simultaneously upwards and downwards. Their position becomes fixed even if wind is blowing (Figure 2).

Fabric or membrane structures are extremely strong while working in tension, so they also provided a new opportunity to bridge large spans, without the drawback of buckling. This is a physical phenomenon that has always limited the possibilities to develop larger spans with compressed thin shells. Tensioned membranes therefore became a step forward in that process towards lightness.
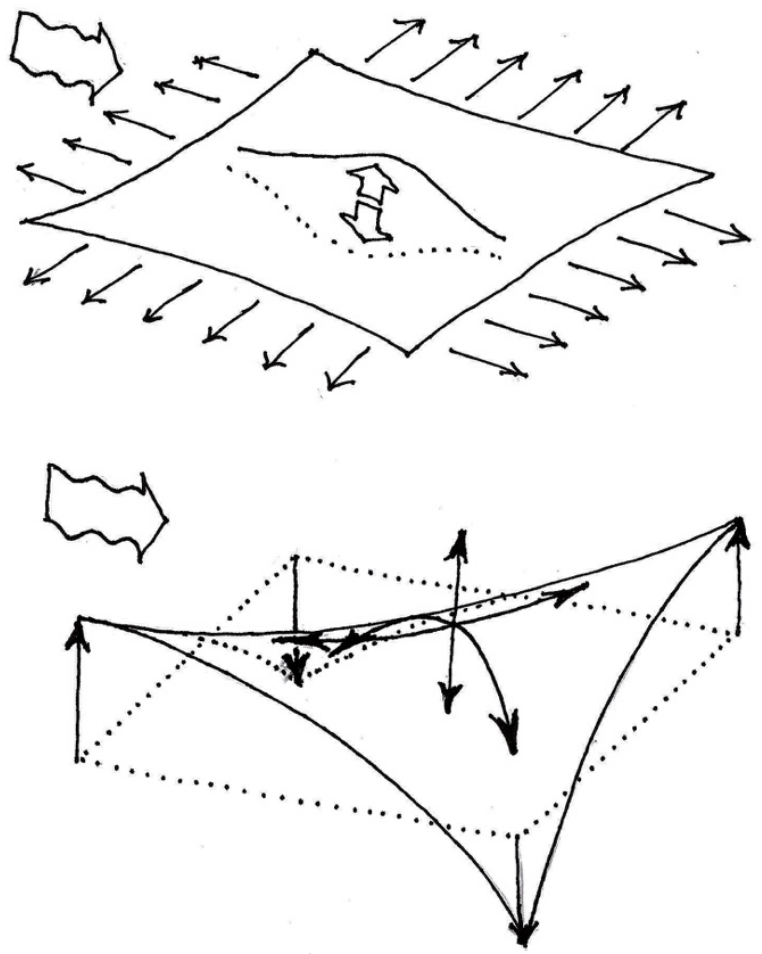

Figure 2. Membrane stiffening by an anticlastic prestressed surface. (C)Author's drawings. 
We are now going to overview some of the new types of prestressed tents developed by Frei Otto in his research work for his doctoral dissertation, and with the collaboration of the tent manufacturing company L. Stromeyer \& Co. They were actually built on the occasion of the German Federal Garden Exhibitions that took place in Kassel (1955), Cologne (1957), and Hamburg (1963).

2.2.1 Anticlastic curved four-point tent: This is the most elementary type derived directly from the basic anticlastic doubly curved minimal surface, developed between two diagonally opposed high and low points.

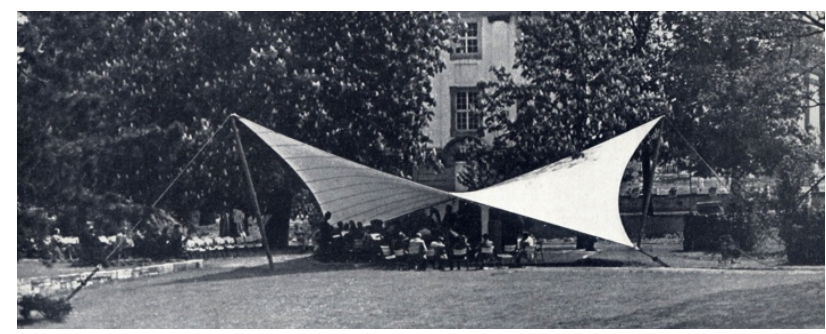

Figure 3. Music Pavilion. Federal Garden Show. Kassel, 1955. (C)Atelier Frei Otto + Partner

These saddle forms were also obtained by Frei Otto with his experiments with soap films, exploring how they develop minimal surfaces. Models were built changing the position of high and low points, using flexible and rigid edges, with straight and curved or regular and irregular linear forms (Figure 4).
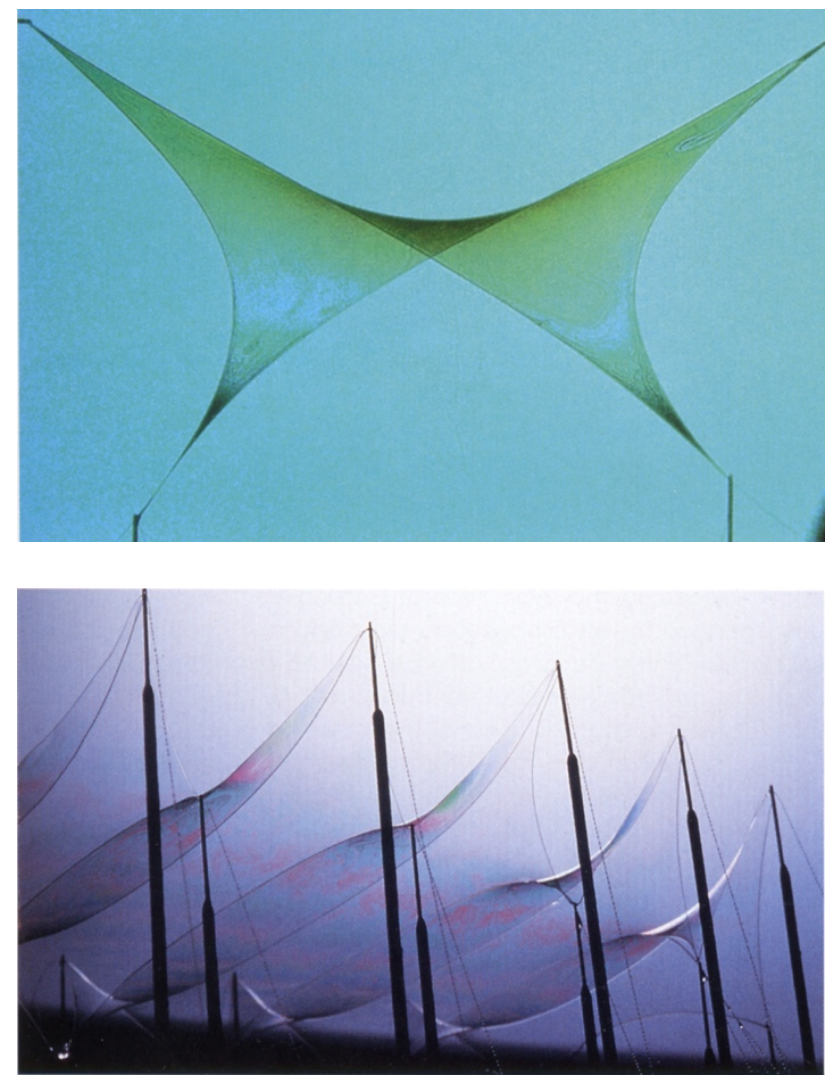

Figure 4. Soap film saddle models. CAtelier Frei Otto + Partner.

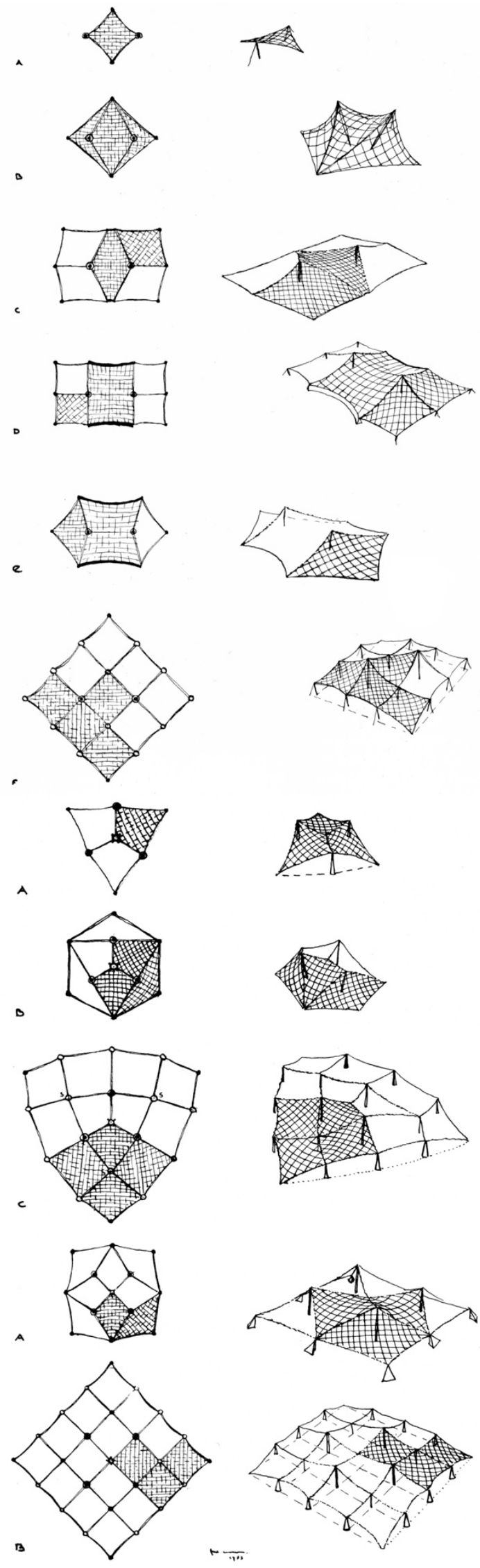

Figure 5. Combinations of saddles developing roofs with two, three, and four high points. CAtelier Frei Otto + Partner. 
2.2.2 Wave tent with ridges and valleys: The main formal feature of this type of prestressed tent is the alternating sequence of high and low points along the membrane edges, generating a pattern of alternating ridges and valleys. The surfaces between them are anticlastic and very appropriate for water draining. This sequence of ridges and valleys creates an undulating longitudinal cross section and depending on their layout the waves can be parallel or radial (Figure 6).
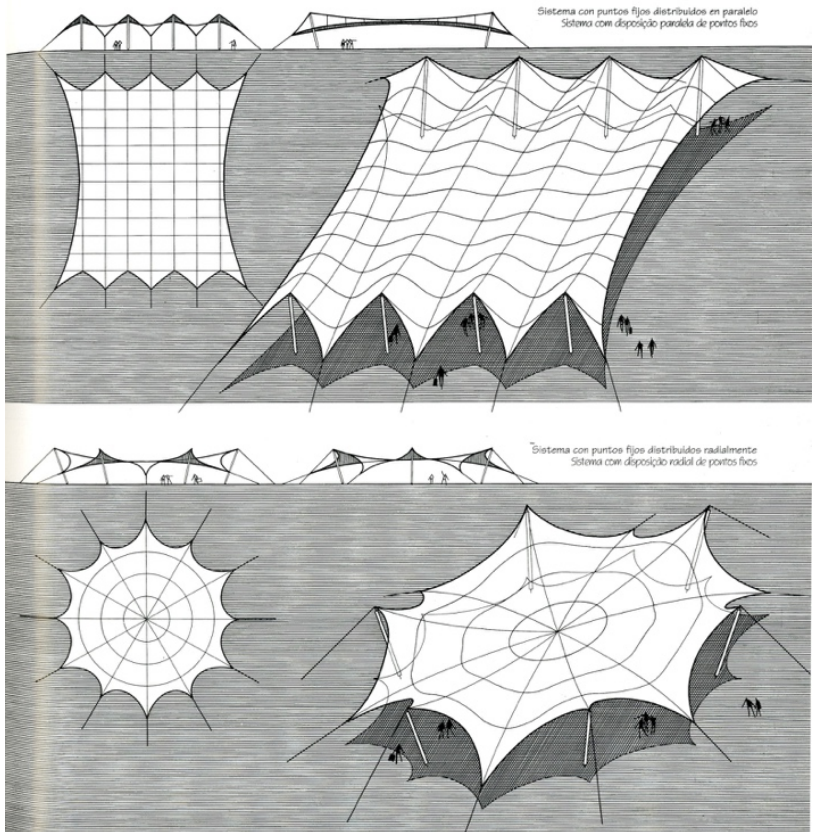

Figure 6. Parallel and star wave tents. CHeino Engel.

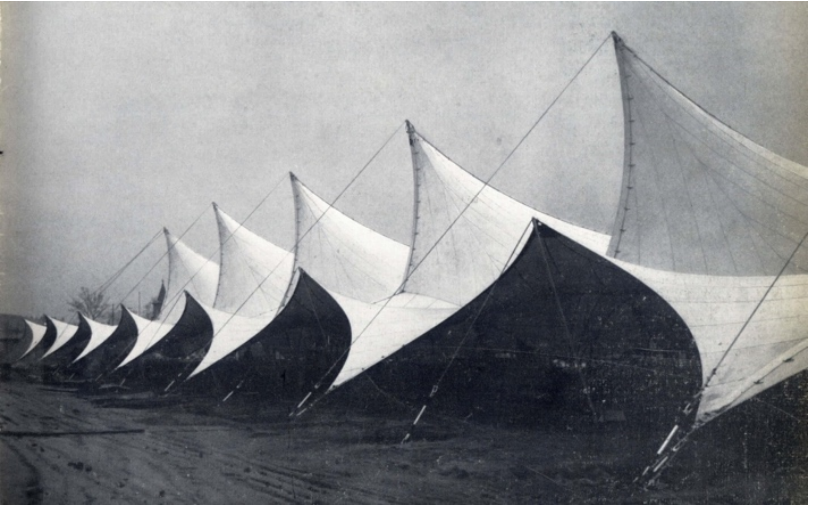

Figure 7. Parallel wave tent. International Garden Show. Hamburg, 1963. CAtelier Frei Otto + Partner.

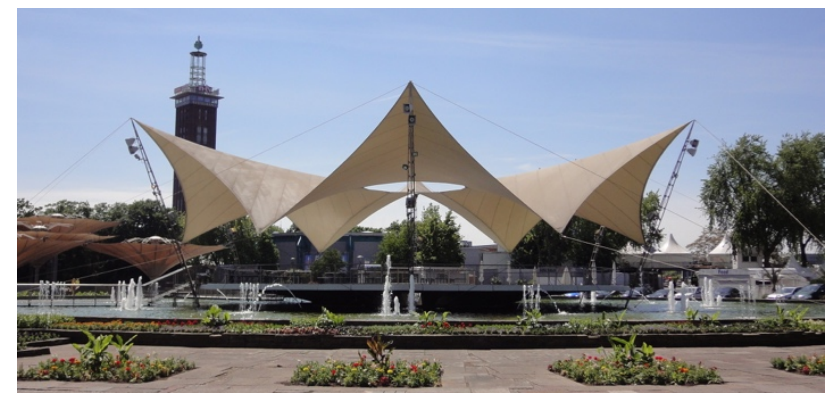

Figure 8. Star wave tent. Dance Pavilion. Federal Garden Show. Cologne, 1957. CAtelier Frei Otto + Partner.
2.2.3 Arch-supported tent: Membranes of this type of tent are prestressed by the anticlastic minimal surface developing between an inner linear rigid arch springing from the tent perimeter, and the tent edges, which can be flexible o rigid linear elements.

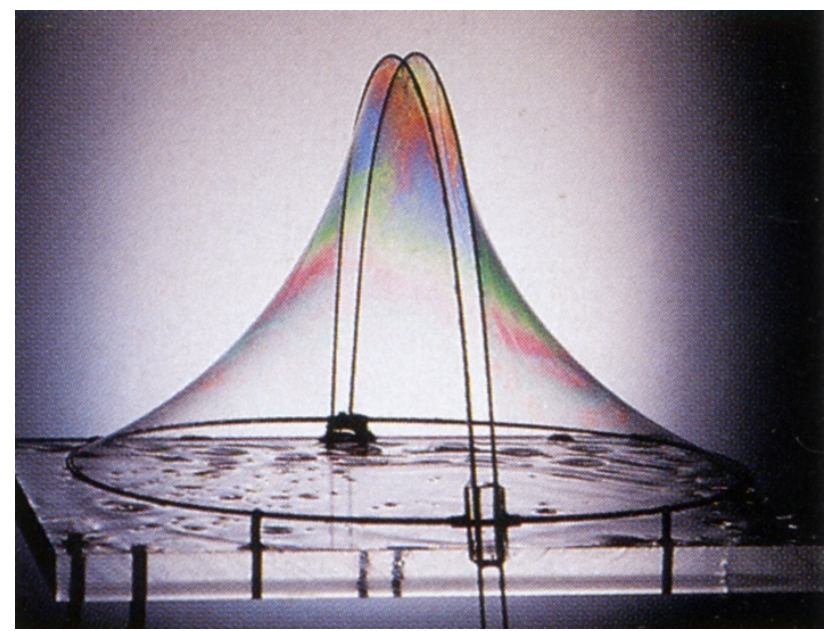

Figure 9. Arch-supported soap film minimal surface model. (C)Atelier Frei Otto + Partner.

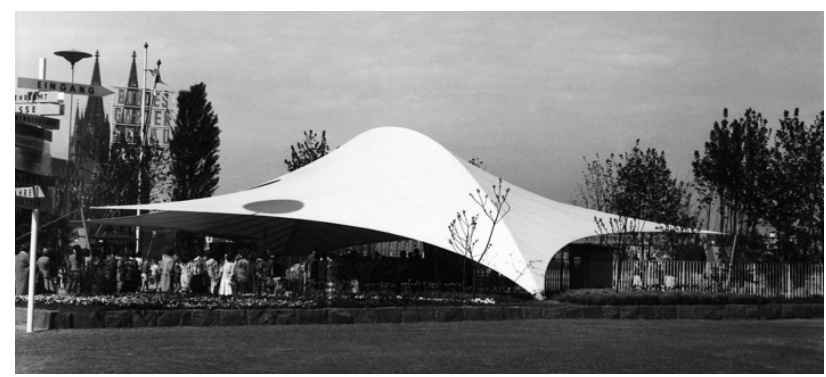

Figure 10. Arch-supported entrance canopy. Federal Garden Show. Cologne, 1957. CAtelier Frei Otto + Partner.

2.2.4 Pointed, humped, and high-and-low-point tent: Prestressed anticlastic surfaces are generated in this type of tent by inserting internal high points, or low points, or a combination of both. A key problem here is the stress concentration at those internal points of the membrane. Frei Otto designed different intermediate elements between these internal points and the membrane to gradually reduce and distribute evenly these high stresses within the membrane.

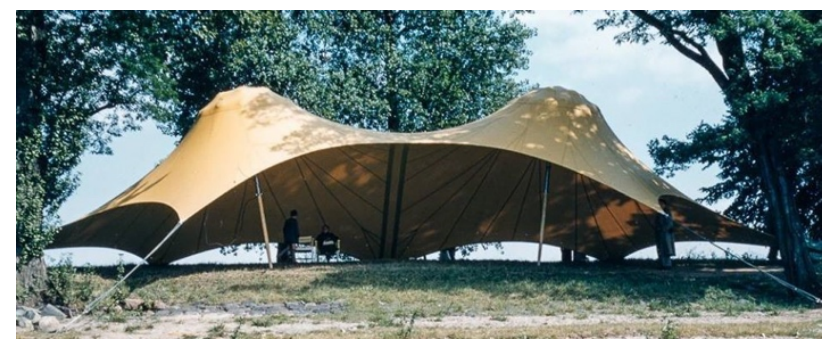

Figure 11. Humped tent. Federal Garden Show. Cologne, 1957. (C)Atelier Frei Otto + Partner. 


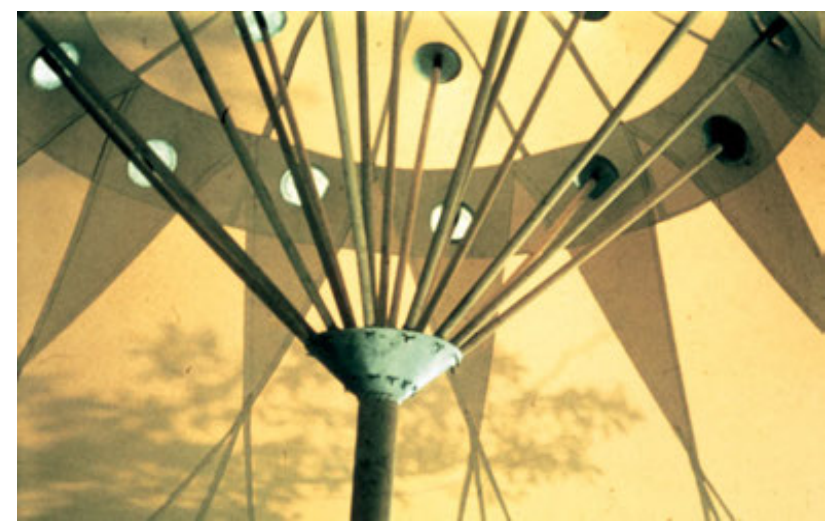

Figure 12. Mast tip split in a bundle of rods. Federal Garden Show. Cologne, 1957. (CAtelier Frei Otto + Partner.

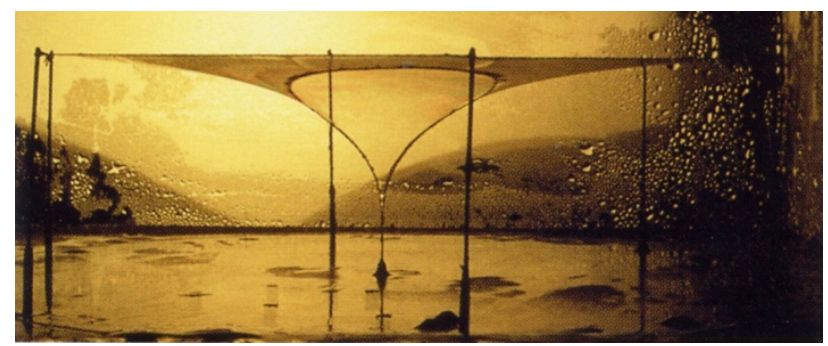

Figure 13. Soap film minimal surface with a low point made up by a loop pulled downwards. (CAtelier Frei Otto + Partner.

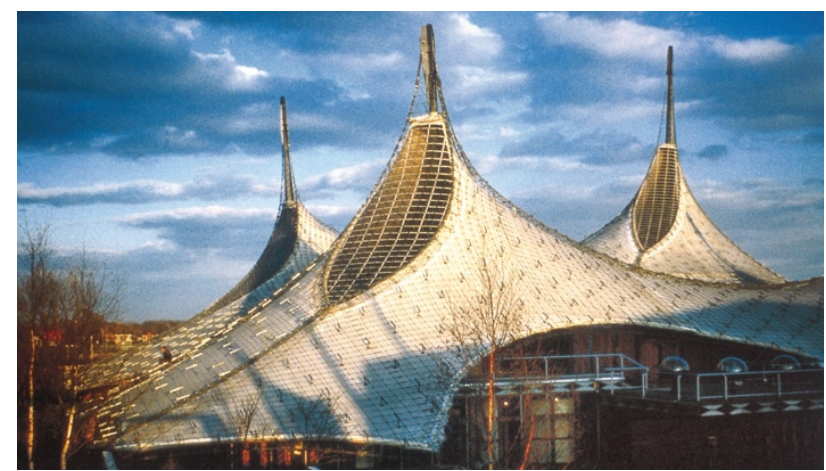

Figure 14. High point with a cable loop in a cable net. German Pavilion. Montreal Expo 1967. CAtelier Frei Otto + Partner.

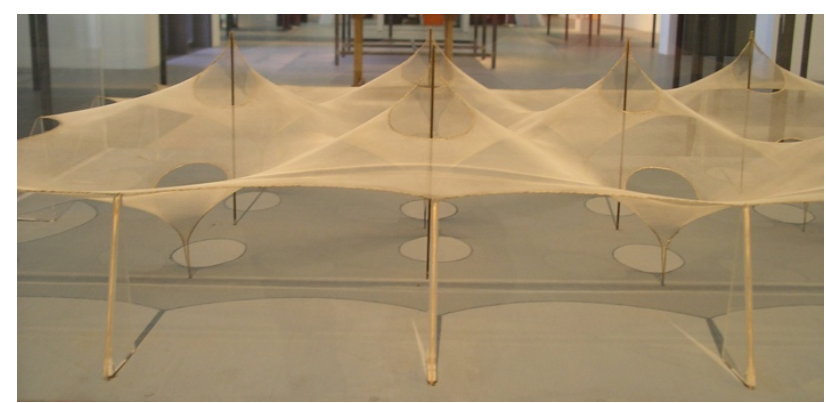

Figure 15. High-and-low-point tent model. (CAuthor's photograph.

\section{YURTS AND GRIDSHELLS}

\subsection{Kyrgyz and Kazakh yurts, and the Mongol Ger:} UNESCO Intangible Cultural Heritage

"Traditional knowledge and skills in making Kyrgyz and Kazakh yurts (Turkic nomadic dwellings)" were inscribed in 2014 on the Representative List of the Intangible Cultural Heritage of Humanity, and "Traditional craftsmanship of the Mongol Ger and its associated customs" were also inscribed on the same list in 2013. Both the yurt and the Mongol ger belong to a particular type of framed tent, a round structure of easily foldable wooden lattice walls, poles and a round roof covered with canvas and felt and tightened with ropes.

The yurt must be light enough to be carried by nomads, flexible enough to be folded and packed, and sturdy enough for multiple assembling and dismantling. Its form is very similar to a dome, a doubly curved synclastic surface enclosing maximum volume with minimum surface area, most suitable to withstand fierce winds, which flow easily around and over this aerodynamic shape. A yurt can be put up or taken down in less than an hour (Faegre, 1982).

\section{The Walls}
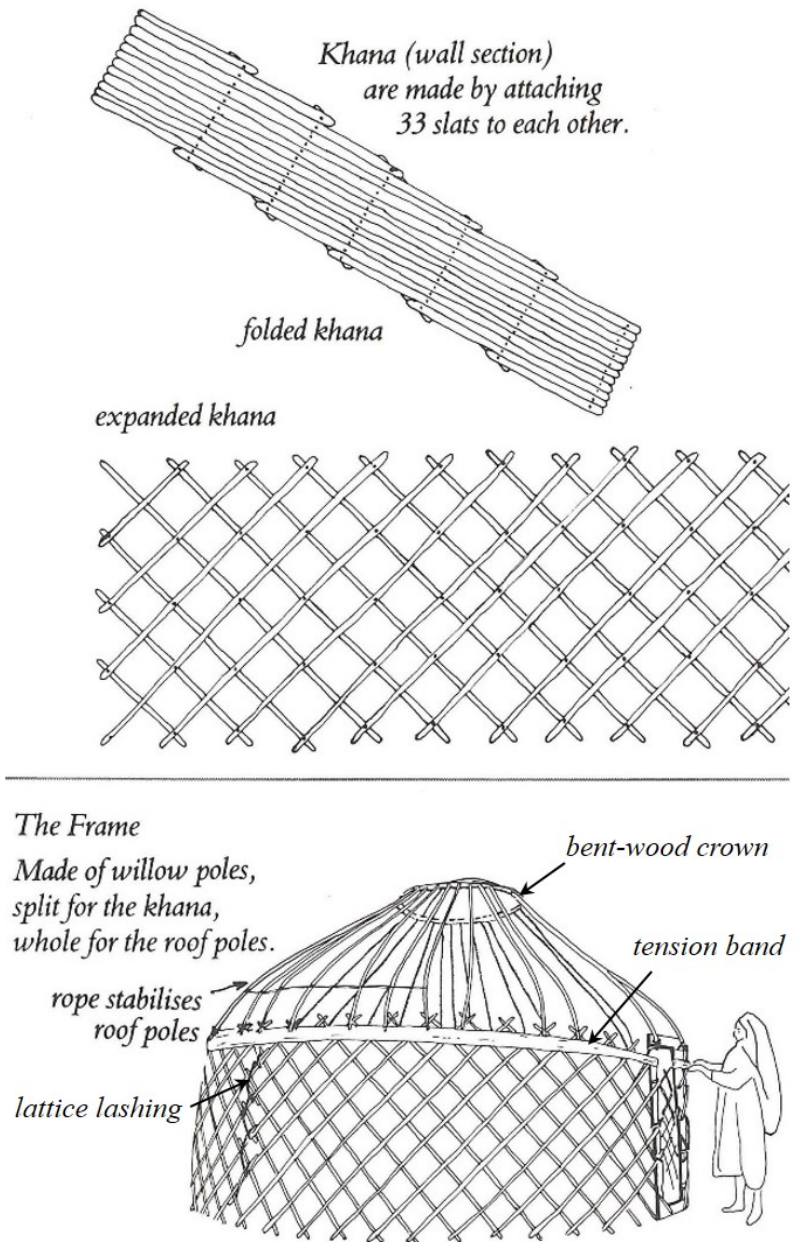

Figure 16. Yurt frame construction.

(C) Faegre, T., 1982: The Kazak Yurt. Mimar (4), p. 50. 
The yurt structural frame includes thin linear flexible wooden rods. The wall is cylindrical and is assembled by lashing sections (khanas) which are made up by a foldable diagonal lattice of laths which forms a square mesh when expanded. There is a hinged joint at each crossing of the wooden laths to allow the folding and expanding movement. Each roof pole rests its bottom end on a criss-cross at the top of the wall lattice, whereas its top end is inserted in a bent wooden circle: the crown (Figure 16).

The roof and walls are tied together, but the compressed roof poles generate an outward thrust that must be absorbed by a tension woven band tied around the top of the wall (Figure 16).

It is important to highlight in the yurt frame the structural possibilities offered by the foldable square-mesh lattice of flexible wooden laths, when expanded and curved. By slightly bending the wooden laths, the lattice develops from a flat surface into a simply curved cylindrical surface, able to withstand compression forces.

\subsection{Gridshells, a new structural type}

Frei Otto experimented with square-mesh timber lath grids, to build compression resistant vaults. He developed a new structural type, that he called Gitterschale, which was translated into English as gridshell. It was actually a new type of shell, much lighter than thin reinforced concrete or ceramic shells, and without an opaque or continuous surface. It was a shell made up of a grid of timber laths, i.e. linear rods, leaving large voids between them, and therefore much surface to allow natural light through it.

Experiments with hanging cloths soaked in plaster to find out the most suitable form for a vault to work only in compression, considering gravity force only, were quite familiar to Frei Otto, as he recalls from his child years in his father's sculpture workshop (Wilhelm, 1985).

If gridshells were meant to be light structures built with linear elements subjected mainly to compressive forces, the use of hanging chain net models became a key feature in their design or form-finding process (Figures 17 and 18). It was in fact Hooke's principle of inversion: "As hangs the flexible line, so but inverted will stand the rigid arch." If a hanging chain adopts the form of a catenary line to ensure that only tension and no compression or bending forces develop, in accordance with its optimal structural behaviour, the inverted catenary becomes the optimal form for an arch, which under gravity must be subjected to compressive forces only, and no bending or tension. This is the first principle for the design of gridshells.

The second principle of gridshell construction is very closely linked to its building process. A planar orthogonal square-mesh slat grid is deformed into a doubly curved synclastic surface. During this process the thin slats or laths are slightly bent, and rotate at each grid crossing or node, changing the original right angles into oblique ones, and the initial mesh squares into rhombi. Once the flexible slat grid has reached the funicular shape obtained through the hanging chain net model, it is stiffened by fixing the angles and tightening the nodes at each grid crossing (Figures 19 and 20).

The first experimental gridshells built by Frei Otto in 1962 were developed with two different boundary conditions, which help us to identify two different types of gridshells: open mesh arch boundary gridshells and closed flat boundary gridshells (Engel, 1997).
3.2.1 Open mesh arch boundary gridshells: The edges of the gridshell coincide with the peripheral grid lines. All the meshes of the grid are closed and complete. The outline of the flat grid is a square or a rectangle. Supports are punctual.
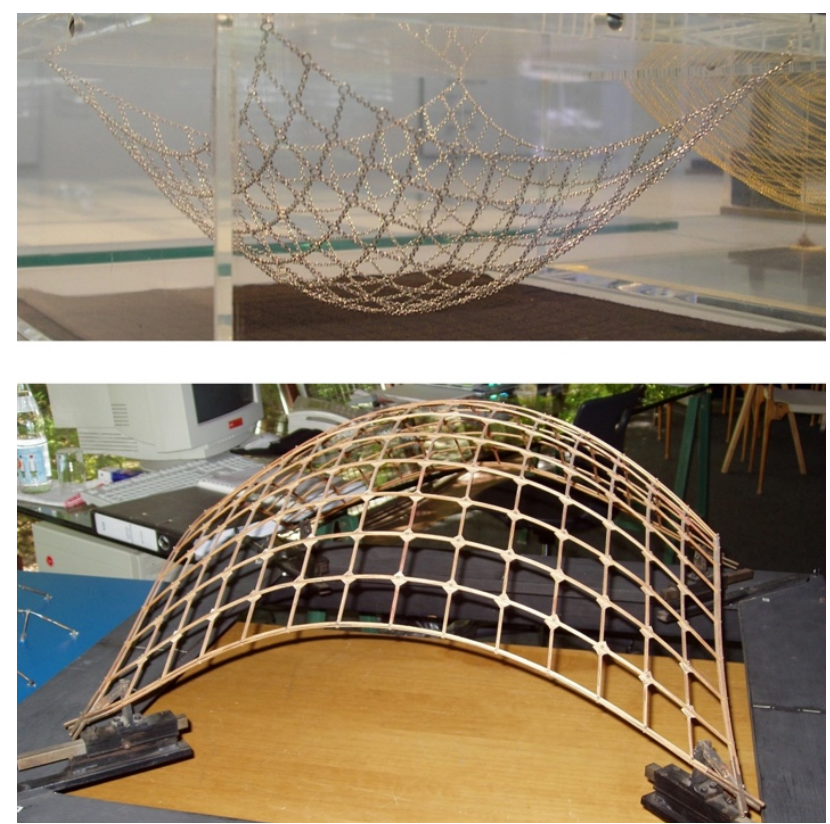

Figure 17. Hanging chain net with open mesh arch boundary, and inverted funicular model. (C)Author's photographs.

3.2.2 Closed flat boundary gridshells: The edges of the gridshell do not coincide with any grid line. The boundary edges can have any form, and the ends of the laths are fastened to them. The peripheral meshes of the grid are cut, open and incomplete. Supports are linear.
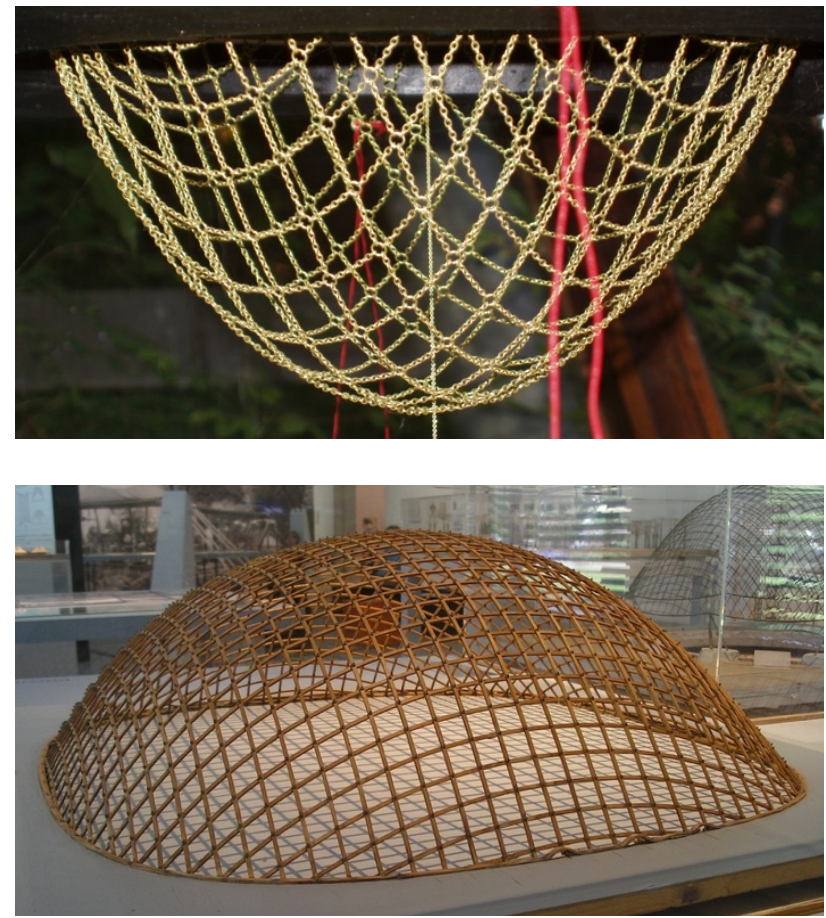

Figure 18. Hanging chain net with close flat boundary, and inverted funicular model of Frei Otto's Deutsche Bauaustellung gridshell. Essen, 1962. CAuthor's photographs. 


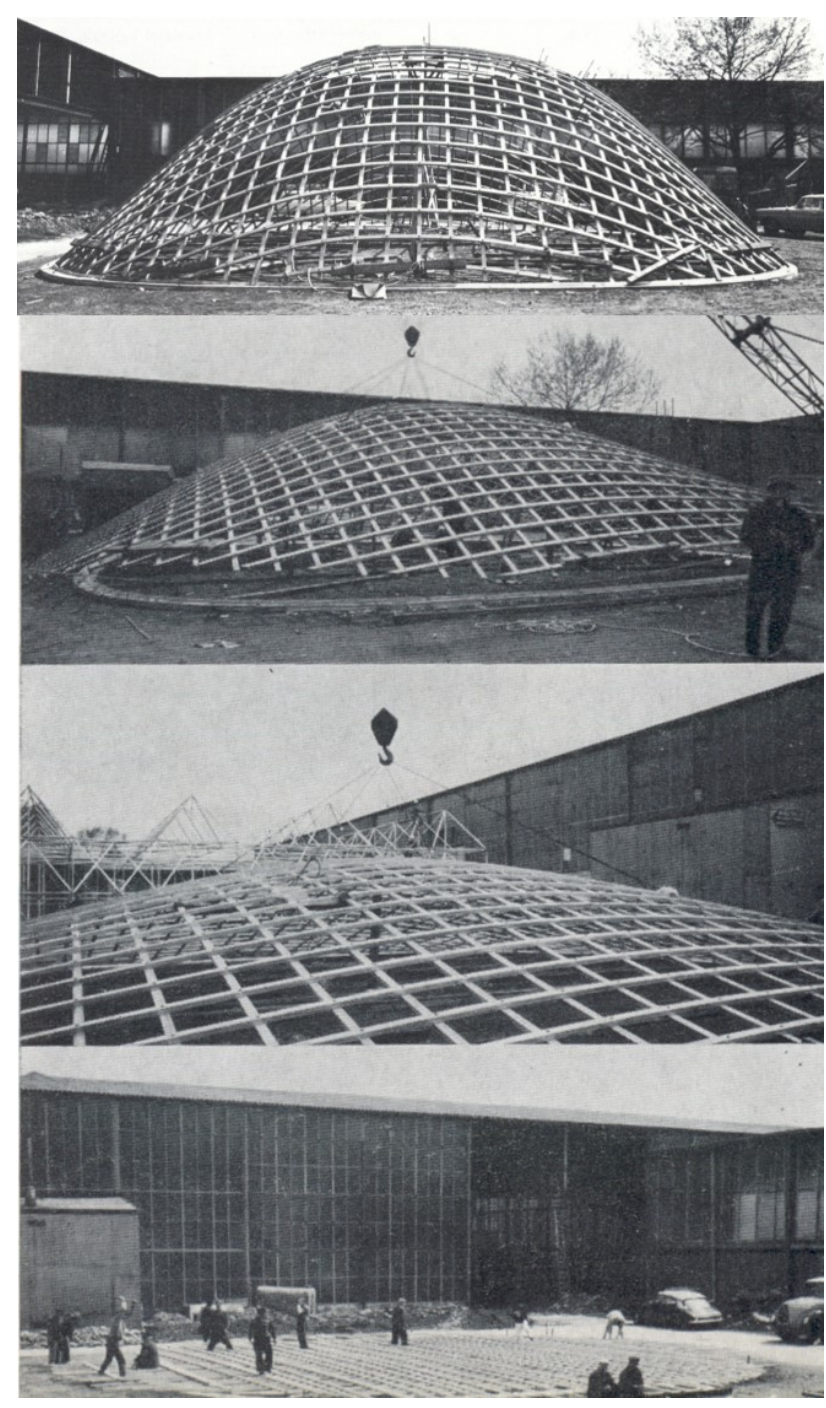

Figure 19. Building process of Frei Otto's Deutsche Bauaustellung gridshell. Essen, 1962. CAtelier Frei Otto + Partner.
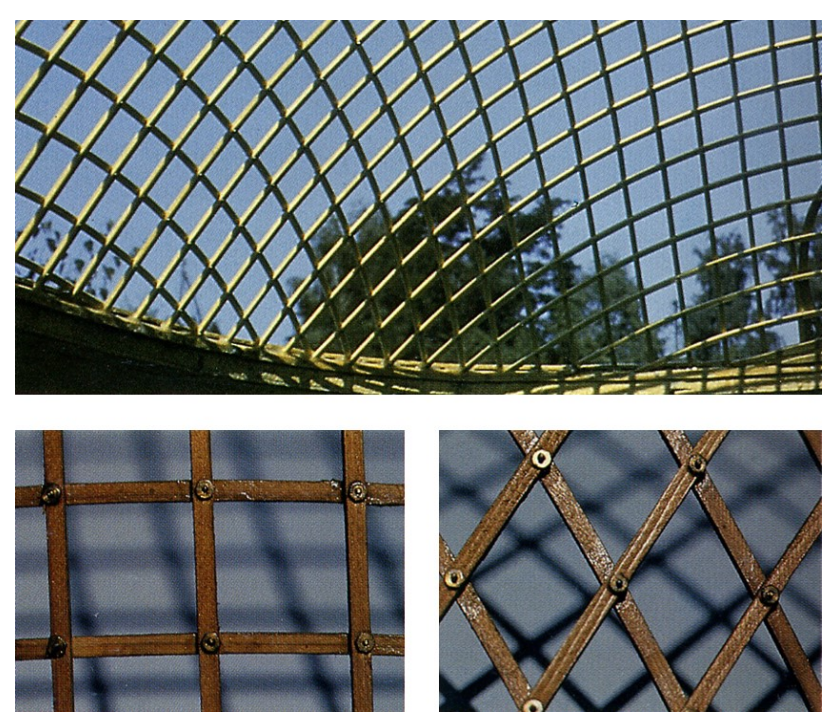

Figure 20. Doubly curved synclastic shape develops as grid is hoisted up, laths rotate at intesections, and initial mesh squares deform into rhombi. CAtelier Frei Otto + Partner.

\subsection{Mannheim Multihalle gridshell}

The work that best exemplified the possibilities of gridshells was the Multihalle Pavilion for the Bundesgartenschau (Federal Garden Show) that took place in Mannheim in 1975. Frei Otto and his collaborators were consultants of the architects Mutschler, Langner and partners, who also counted on the technical assistance of the engineer Edmund Happold, from Ove Arup.

The pavilion had a multipurpose hall and a restaurant, linked with a footbridge corridor, all covered with a unified antifunicular gridshell roof, made up by a $50 \mathrm{~cm}$ square-mesh grid of continuous timber laths. The antifunicular shape of the roof was obtained through a hanging chain net model with a free-form flat boundary edge (Figure 21).

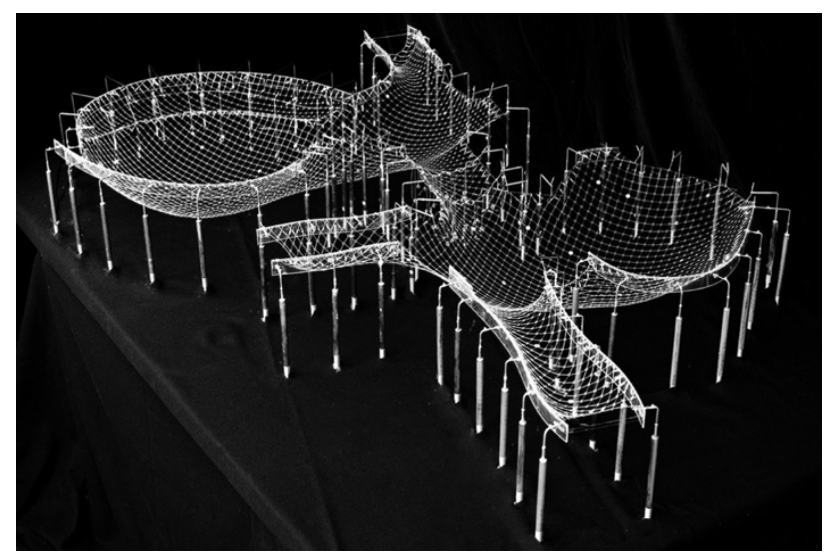

Figure 21. Frei Otto's hanging chain net funicular model of Mannheim Multihalle gridshell. (CAtelier Frei Otto + Partner.

The building process started with the orthogonal grid lying flat on the ground, and a bolt at each node inserted, but untightened, as a pinned connection, so that the crossing laths could rotate freely when the grid was lifted. The grid was then gradually hoisted up through scaffolding towers at specific points and heights, to reach the antifunicular doubly curved shape obtained with the hanging chain model. Once this shape was achieved, bolts at each node were tightly fastened, the lath ends were connected to the boundary edges, and the gridshell became stiffened.

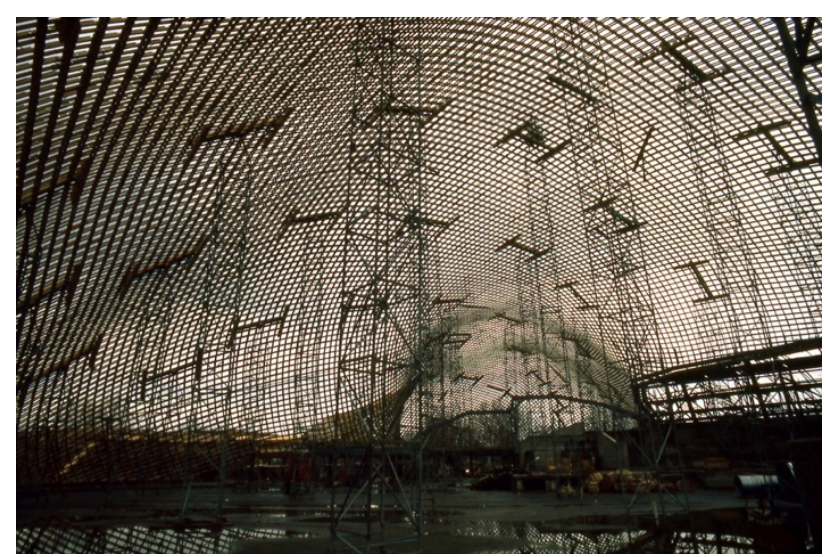

Figure 22. Building process of Mannheim Multihalle gridshell. CAtelier Frei Otto + Partner. 
With a covered surface of $7400 \mathrm{~m}^{2}$, a maximum span of $60 \mathrm{~m}$ and a maximum height of $20 \mathrm{~m}$, this work is still nowadays one the world's largest timber gridshells and lightest compression structures ever built (Otto et al., 1978).
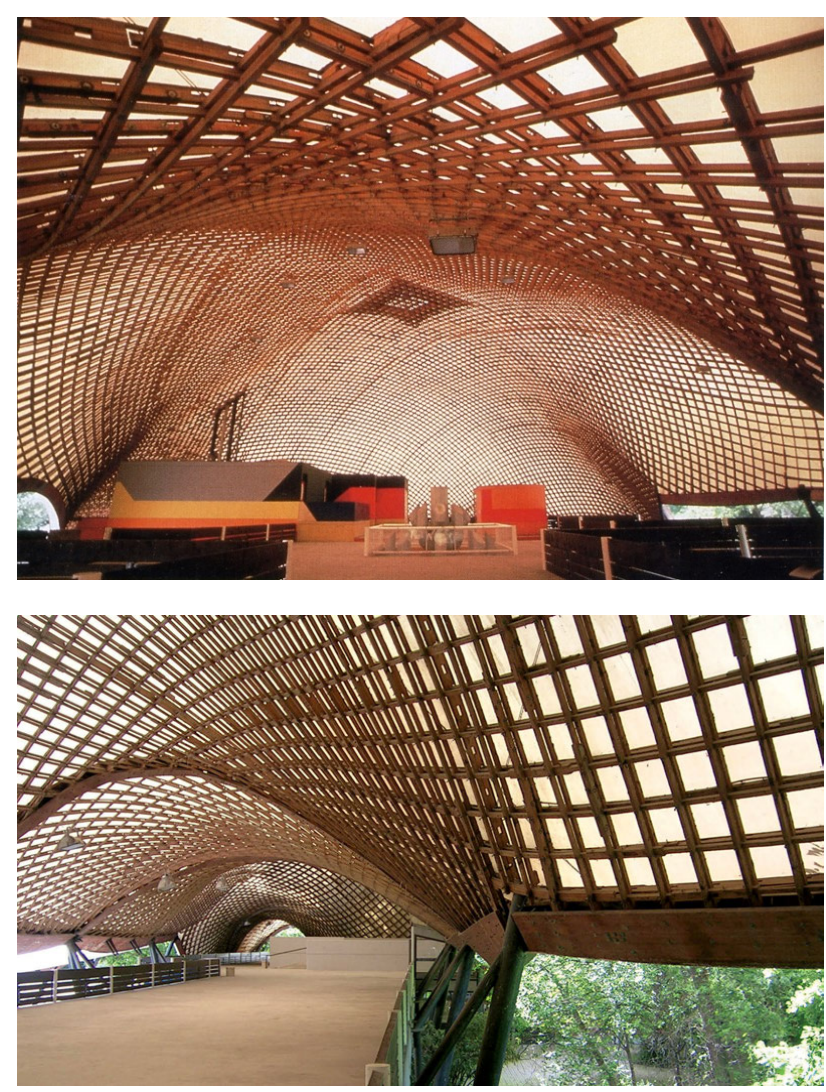

Figure 23. Inner space of Mannheim Multihalle gridshell. (C) Atelier Frei Otto + Partner.

\section{CONCLUSION}

In this itinerary we have been following to inquire into the sustainability lessons underlying the relationship between vernacular architecture and Frei Otto's work, attention has been focused on tents, membrane structures, yurts and gridshells. Tents and yurts are only a small part of vernacular architecture, that architectural historians and theoreticians have even considered as archetypes of architecture. Membrane structures and gridshells are also a small part of Frei Otto's work, which also embraced many other types of light structures, like nets, branching, pneumatic structures, or retractable roofs. But these new types of light structures he invented cannot reflect the rich legacy of his contribution to architecture, which also involved a commitment to investigating the processes of form generation in nature, technology, and architecture, searching for common principles, and exploring all types of materials and physical processes.

This short survey has proved that Frei Otto's attitude towards vernacular architecture was not based on form imitation, but on a deep understanding of the physical phenomena that drive form towards optimization, like minimal surfaces developed by soap film models, or antifunicular forms designed to work only in compression, developed by hanging chain net models. Tents and yurts are also optimized constructions taking full advantage of the traditional materials used, like fabric or foldable timber lattices, to develop light and strong structures.
This close relationship between form, force and mass, not only in vernacular architecture, but also in all objects of nature and technology, was a permanent object of research for Frei Otto. From his early work on, he considered the principle of lightweight construction as a way of building with a minimum consumption of material, energetic, and economic means, a key feature of sustainability. In accordance with this approach, form is no longer regarded as something to be imposed beforehand, but as a result of a process of searching.

After finding sustainability lessons of vernacular architecture in Frei Otto's work, this paper concludes with an example of a contribution of Frei Otto's work to vernacular architecture, a self-built reed gridshell, to illustrate the different gridshells that have so far been built with bamboo in different places of the world, and the possibilities of this sustainable building material.

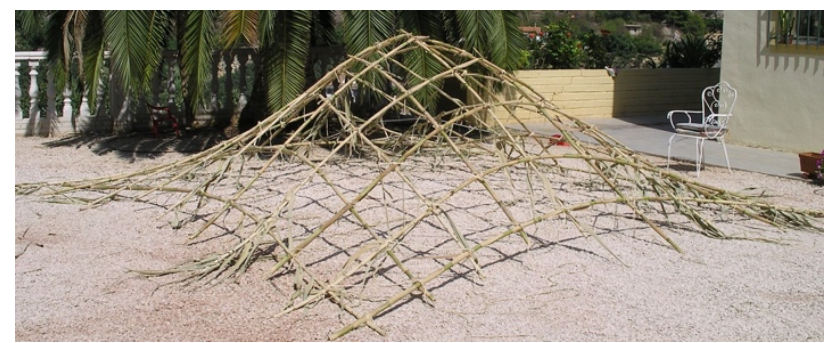

Figure 24. Self-built reed gridshell. (CAuthor’s photograph.

\section{REFERENCES}

Burkhardt, B., 2000: Geschichte des Zeltbaus. History of Tent Construction. Detail (6), 960-964.

Drew, P., 1979: Tensile architecture. Crosby Lockwood Staples, London.

Engel, H., 1997: Structure Systems. Gerd Hatje, Ostfildern-Ruit.

Faegre, T., 1982: The Kazak Yurt. Mimar (4), 50-55.

Hennicke, J., Hasegawa, T., 1974: Gitterschalen / Grid shells. IL 10. Institut für leichte Flächentragwerke, Stuttgart.

Le Ricolais, R., 1997: Visiones y paradojas. Visions and paradox. Fundación Cultural COAM, Madrid.

Meissner, I., Möller, E., 2015: Frei Otto. Forschen, bauen, inspirieren. A life of research, construction and inspiration. Detail, Munich.

Nerdinger, W., Meissner, I., Möller, E., Grdanjski, M., 2005: Frei Otto: complete works: lightweight construction natural design. Birkhäuser, Basel.

Otto, F., Songel, J. M., 2010: A conversation with Frei Otto. Princeton Architectural Press, New York.

Otto, F., Burkhardt, B., Bächer, M., 1978: Multihalle Mannheim. IL 13. Institut für leichte Flächentragwerke, Stuttgart.

Roland, C., 1972: Frei Otto: structures. Longman, London.

Wilhelm, K., 1985: Portrait Frei Otto. Quadriga-Verlag Severin, Berlin. 